\title{
Non-surgical intervention for retroperitoneal lymphogenic and pulmonary metastases of a benign leiomyoma: treatment with ulipristal acetate
}

\author{
Kim E Kortekaas, Harold M P Pelikan
}

Department of Obstetrics and Gynaecology, Haaglanden Medical Center, Den Haag, The Netherlands

\section{Correspondence to} Dr Harold M P Pelikan, h.pelikan@live.nl

Accepted 13 December 2017

\section{SUMMARY}

This case report describes a very rare coexistence of retroperitoneal lymphogenic and pulmonary metastases of a benign leiomyoma: benign metastasising leiomyoma $(B M L)$. Despite surgical treatment growth of multiple nodules in the lungs, omentum, mesenterium and retroperitoneum was observed by CT scan. We started off-label ulipristal acetate treatment with impressive results. The lesions on the CT scan disappeared, and the patient was asymptomatic after treatment.

\section{BACKGROUND}

Although leiomyomas are benign, some rare forms of leiomyomas have unusual growth, such as benign metastasising leiomyoma (BML). They represent the extrauterine spread of multiple smooth muscle nodules frequently located in the lung, abdominal cavity, retroperitoneum, muscular tissue, lymph nodes, blood vessels or heart. ${ }^{1}$ The aetiology of these tumours remains controversial. Although these lesions have cancer-like properties, they are slow growing and have a good prognosis. Due to the rarity of BML cases, there is limited literature and the underlying pathophysiology and disease course are unknown.

In this case report, we present an extraordinary case of BMLs with retroperitoneal lymphogenic and pulmonary metastases after supracervical

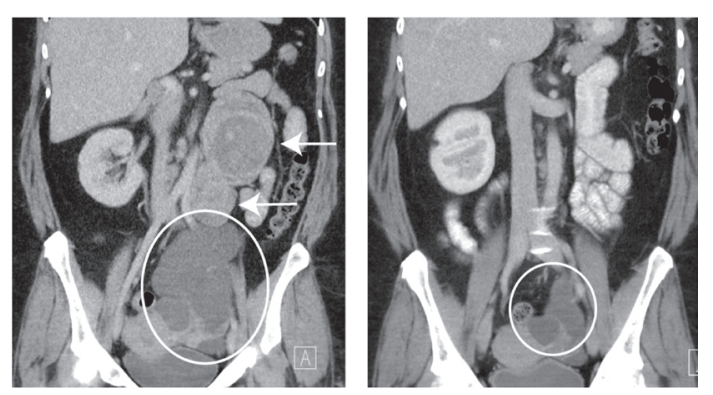

Figure 1 CT scan before (left) and after treatment with ulipristal acetate (right). The arrows in the left image indicate the retroperitoneal enlarged lymph nodes and the circle indicates the multicystic process in the pelvis (pseudocyst). This is the situation before ulipristal acetate treatment. The right image shows the situation after 16 months of ulipristal acetate treatment: the enlarged lymph nodes are not detectable anymore and the size of the pseudocyst has diminished. hysterectomy that was successfully treated with ulipristal acetate. To the best of our knowledge, only one case report has been described where BMLs were successfully treated with ulipristal acetate. ${ }^{2}$

\section{CASE PRESENTATION}

In 2007, a 38-year-old woman, para 0, suffered from menorrhagia and dysmenorrhoea since threeyears. Her medical history showed anticyclic citrullinated peptide negative erosive rheumatoid arthritis, epilepsy, hypertension and diabetes mellitus. Ultrasound showed a subserous myoma with possible necrosis, which was treated unsuccessfully by multiple non-invasive treatments. Therefore, an uncomplicated abdominal enucleation of the leiomyoma and supracervical hysterectomy was performed. Final histopathological diagnosis revealed adenomyosis and benign leiomyomas.

Seven years later, the patient suffered from abdominal pain. By ultrasound and on CT scan, a multicystic process in the left lower abdomen $(52 \times 55 \mathrm{~mm})$ was seen with retroperitoneal and pulmonary lymph node metastases (figure 1, left). CA-125 levels and liver biochemistry were normal. An exploratory laparotomy was performed. After extended pelvic adhesiolysis, two normal ovaries, Fallopian tubes, cervical stump and appendix were found. The multicystic process seen on imaging was caused by the adhesions. In the upper abdomen, above the aortic bifurcation, three enlarged lymph nodes were found and excised. The largest had a diameter of $3 \mathrm{~cm}$. Between the aorta and the left kidney, two tumours were found of, respectively, 6 and $9 \mathrm{~cm}$. Both were excised after meticulous dissection of the vascularisation of the left kidney. Both these tumours and the three excised lymph nodes revealed benign smooth muscle tissue at histopathological analysis. After comparing this smooth muscle tissue with the histopathological findings of the tissue excised in 2007, the diagnosis of BML was made.

A year after the excision by laparotomy, we noticed growth of the pseudocyst in the left lower abdomen by ultrasound, which was confirmed by CT scan. Also, the multiple nodules in the lungs, omentum, mesenterium and retroperitoneum were observed. A case report of Verguts et al, ${ }^{2}$ described symptom relief of leiomyomatosis peritonealis disseminata with ulipristal acetate treatment. We started ulipristal acetate $5 \mathrm{mg}$ once daily off-label 
after consulting the manufacturer and counselling our patient. Follow-up was performed after 3, 6, 12 and 16 months by CT scan. The preaortic lymph nodes decreased from $18 \mathrm{~mm}$ to $11 \mathrm{~mm}$ to not even detectable size, respectively. Also the multicystic process based on adhesions diminished (figure 1, right). At this moment, our patient is symptom free and does not use ulipristal acetate since 8 months; in total she used ulipristal acetate $5 \mathrm{mg}$ once daily for 16 months.

\section{DIFFERENTIAL DIAGNOSIS}

The working diagnosis was a (malignant) ovarian tumour with retroperitoneal and pulmonary lymph node metastases, despite the lack of ascites and no elevated CA-125 levels. Our differential diagnosis contained infectious pulmonary granulomata, pulmonary sarcoidosis (nodular), rheumatic nodules and pulmonary amyloidosis.

\section{TREATMENT}

Although ulipristal acetate (a selective progesterone receptor modulator) is frequently used as an effective treatment for uterine fibroids. However, the effect of ulipristal acetate on BML is unknown. Verguts et $a l^{2}$ have described the first and only case report of a patient with BML treated with ulipristal acetate.

Ulipristal acetate reduces proliferation of leiomyoma cells, remodels extracellular matrix and induces apoptosis. Another action of ulipristal acetate includes inhibition of gonadotropin secretion and suppression of ovarian function, which contributes to a hypoestrogenic environment. This will induce endometrial hypotrophy and shrinkage of the fibroids. ${ }^{3}$ Verguts et al ${ }^{2}$ questioned whether endometrial atypical hyperplasia could develop after treatment with ulipristal acetate. Recently, it has been thoroughly studied that these changes are reversible and benign. ${ }^{4}$ These endometrial changes are referred to as progesterone receptor modulator associated endometrial changes (PAEC). ${ }^{5}$

With this case report, we confirm a possible and novel non-surgical treatment of BML.

\section{OUTCOME AND FOLLOW-UP}

Both subjective and objective response on ulipristal acetate treatment was impressive.

Follow-up was performed by CT scan, and showed that the preaortic lymph nodes decreased in size from $18 \mathrm{~mm}$ to $11 \mathrm{~mm}$ to not even detectable size, respectively. Also the multicystic process based on adhesions diminished (figure 1, right). Our patient is symptom free and does not use ulipristal acetate since 8 months; in total she used ulipristal acetate $5 \mathrm{mg}$ once daily for 16 months.

Her follow-up schedule includes 3-6 months outpatient clinic visits and yearly CT scan during 5 years of follow-up.

\section{DISCUSSION}

To our knowledge, there is only one other case report that describes the coexistence of retroperitoneal lymphogenic and pulmonary metastases of a benign leiomyoma. ${ }^{1}$ Next to that, according to our knowledge, BML has mostly been described after complete hysterectomy; one other case report describes a supracervical hysterectomy like this report. ${ }^{6}$ Also, we confirmed the finding of Verguts $e t a l^{2}$ that there is a role for ulipristal acetate in reducing the size of the BML nodules since these

\section{Patient?}

In 2015, I was operated and a leiomyoma was removed from my pelvis. I recovered slowly. My abdomen and pelvic area hurt a lot. After a while, I had (vaginal) blood loss. Then I started using Esmya. The blood loss stopped. After 1 month, I felt better. Nowadays, I don't take that medicine any more.

\section{Learning points}

- Benign metastasising leiomyoma (BML) is a rare diagnosis, but should not be ruled out when nodules in the retroperitoneum and lungs are seen after myomectomy or (supracervical) hysterectomy.

- In case of BML, a non-surgical treatment as ulipristal acetate should be considered.

- Long term follow-up must be warranted because the natural course of BML is unknown.

- The diagnosis of BML is not only possible after complete hysterectomy but also after supracervical hysterectomy.

lesions express progesterone receptors (figure 1, right). This is the first case report of retroperitoneal lymphogenic and pulmonary metastases of benign leiomyoma that was treated with ulipristal acetate. The latter is a selective progesterone receptor modulator. The hypothesis is that ulipristal acetate successfully blocks the progesterone receptors of the lesions in which the growth of the lesions is restrained. The CT scan showed impressive reduction of the lesions, and the patient is asymptomatic at this moment. Endometrial changes induced by ulipristal acetate have been described after long-term use. But these changes are benign and reversible. 4

Contributors Both authors equally contributed to the conception or design of the work, figure interpretation, critical revision of the article and final approval of the version to be published. KK was involved in the drafting of the article.

Competing interests None declared.

Patient consent Obtained.

Provenance and peer review Not commissioned; externally peer reviewed. (C) BMJ Publishing Group Ltd (unless otherwise stated in the text of the article) 2018. All rights reserved. No commercial use is permitted unless otherwise expressly granted.

\section{REFERENCES}

1 Lim SY, Park JC, Bae JG, et al. Pulmonary and retroperitoneal benign metastasizing leiomyoma. Clin Exp Reprod Med 2011;38:174-7.

2 Verguts J, Orye G, Marquette S. Symptom relief of leiomyomatosis peritonealis disseminata with ulipristal acetate. Gyneco/ Surg 2014;11:57-8.

3 Biglia N, Carinelli S, Maiorana A, et al. Ulipristal acetate: a novel pharmacological approach for the treatment of uterine fibroids. Drug Des Devel Ther 2014;8:285-92.

4 Donnez J, Donnez O, Dolmans MM, et al. Safety of treatment of uterine fibroids with the selective progesterone receptor modulator, ulipristal acetate. Expert Opin Drug Saf 2016;15:1679-86.

5 De Milliano I, Van Hattum D, Ket JCF, et al. Endometrial changes during ulipristal acetate use: a systematic review. Eur J Obstet Gynecol Reprod Biol 2017;214:56-64.

6 Ordulu Z, Dal Cin P, Chong WW, et al. Disseminated peritoneal leiomyomatosis after laparoscopic supracervical hysterectomy with characteristic molecular cytogenetic findings of uterine leiomyoma. Genes Chromosomes Cancer 2010;49:1152-60. 
Copyright 2017 BMJ Publishing Group. All rights reserved. For permission to reuse any of this content visit http://group.bmj.com/group/rights-licensing/permissions.

BMJ Case Report Fellows may re-use this article for personal use and teaching without any further permission.

Become a Fellow of BMJ Case Reports today and you can:

- Submit as many cases as you like

- Enjoy fast sympathetic peer review and rapid publication of accepted articles

- Access all the published articles

- Re-use any of the published material for personal use and teaching without further permission

For information on Institutional Fellowships contact consortiasales@bmjgroup.com

Visit casereports.bmj.com for more articles like this and to become a Fellow 